\title{
EDUCAÇÃO AMBIENTAL NO COMBATE AO “GREENWASHING”
}

\author{
Rosana Rocha Siqueira ${ }^{1}$ \\ Maria A. Mundim Vargas ${ }^{2}$
}

\section{Resumo}

Este artigo tem por objetivo apresentar algumas contribuições normativas de combate ao Greenwashing, considerando a necessidade de diálogo com as práticas de educação ambiental, uma vez que os educadores devem estar atentos para ações publicitárias em produtos e serviços que propagam, mas não colaboram verdadeiramente com ações sócio ambientais. Desta forma considera-se greenwashing como uma prática no âmbito da comunicação e marketing que busca "eco-embranquecer" a imagem pública de produtos, serviços e instituições, com vistas a agregar valores sócio-ambientais destacando-se da concorrência. Diante de práticas abusivas ou falsas na utilização de termos como sustentável e ecológico em rótulos e serviços, o Ministério do Meio Ambiente (MMA), o INMETRO (Instituto Nacional de Metrologia, Normalização e Qualidade), a ABNT (Associação Brasileira de Normas técnicas) e o CONAR (Conselho Nacional de Autoregulamentação Publicitária), revisaram e editaram diversas instruções normativas com vistas a combater a utilização abusiva de termos não comprovados. Com feito para este estudo realizou-se pesquisa bibliográfica exploratória em revistas, livros, e internet, com vistas destacar a importância de novas abordagens em Educação Ambiental que considerem as normativas como base de sensibilização. Pode-se perceber as relações intrínsecas entre o combate ao greenwashing e as práticas de Educação Ambiental.

Palavras-chave: Educação Ambiental; Greenwashing; Publicidade.

\begin{abstract}
This article aims to some normative contributions to combat greenwashing, considering the need for dialogue with the practices of environmental education, since teachers must be aware of actions on advertising products and services that propagate, but not truly collaborate with actions environmental partner. Thus it is considered as a greenwashing practice in communication and marketing that seeks to "eco-whiten" the public image of products, services and institutions, with a view to adding social and environmental values emphasizing competition. Facing abuse or false in the use of terms such as sustainable and eco-labels and services in the Ministry of Environment (MMA), INMETRO (National Institute of Metrology, Standardization and Industrial Quality), ABNT (Brazilian Association of Technical Standards) and CONAR (National Council for Advertising self-regulation), revised and edited several normative instructions in order to combat the misuse of terms unproven. With done for this study was conducted exploratory literature in journals, books, and internet, aiming to highlight the importance of new approaches in environmental education as they consider the normative basis of awareness. Can

1 Mestranda em Desenvolvimento e Meio-Ambiente (PRODEMA/UFS) - Email: hosanalilas393@ yahoo.com.br

2 Professora do Programa de Pós-Graduação em Geografia (NPGEO-UFS) e do Programa de Pós-Graduação em Desenvolvimento e Meio-Ambiente (PRODEMA/UFS) - Email: amundim@ infonet.com
\end{abstract}


Ambivalências - Revista do Grupo de Pesquisa "Processos Identitários e Poder" - GEPPIP V. 01, n. 1, jan-jun/2013.

understand the $\quad$ intrinsic
ght greenwashing practices and $\begin{aligned} & \text { Environmental the } \\ & \text { Education. }\end{aligned}$

Keywords: Environmental Education; Greenwashing; Advertising. 


\section{1 - Apresentação do tema}

Diante da emergência das questões ambientais a educação ambiental surge como uma nova perspectiva de mudança em diversos âmbitos da sociedade, assim como a tecnologia para muitos constitui-se no "toque de Midas" capaz de transformar resíduos em ouro. Neste contexto é sabido que discussões dicotômicas ou receitas práticas que não envolvam a sensibilização e a participação dos atores sociais, não podem de fato surtir efeitos em médio e longo prazo. Neste contexto este artigo pretende apresentar a importância da Educação Ambiental no combate ao chamado greenwashing.

Entende-se por greenwashing as estratégias no âmbito da comunicação e marketing que buscam "eco-embranquecer" a imagem pública de produtos, serviços e instituições, como forma de agregar valor atrelados aos benefícios socioambientais, diferenciando-os perante a concorrência, conquistando assim diferencial competitivo.

Talcontextosurgediantedoaumentodaconcorrênciaentreasempresas, danecessidade de adequar produtos e serviços às normas ambientais e de saúde pública, e as necessidades de consumidores cada vez mais informados sobre as questões socioambientais.

A Educação Ambiental aliada ao combate ao greenwashing, configurando-o como prática abusiva, pode sensibilizar empresas e consumidores a aplicar e reconhecer ações cujas práticas possam realmente ser comprovadas através da oferta de informações claras, uma vez que as embalagens devem trazer informações verdadeiras e com linguagem adequada ao entendimento do público geral.

A desatenção a estes aspectos podem provocar danos ao meio ambiente e infração ao Código de Defesa do Consumidor (Lei $\mathrm{n}^{\circ}$ 8.078, de 11 de setembro de 1990), podem ocorrer diversos prejuízos aos consumidores, inclusive contra sua própria saúde e a catadores de materiais recicláveis, que precisam de indicações confiáveis referentes a composição dos produtos a serem reciclados.

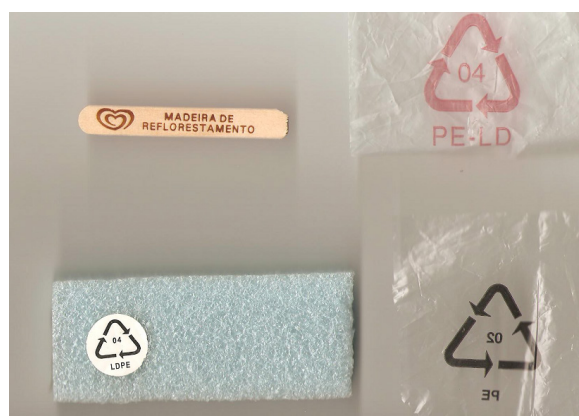

Figura 01 - Padronização de simbologias auxilia na identificação de materiais nas embalagens. Fonte: Embalagem de produto, arquivo pessoal. 


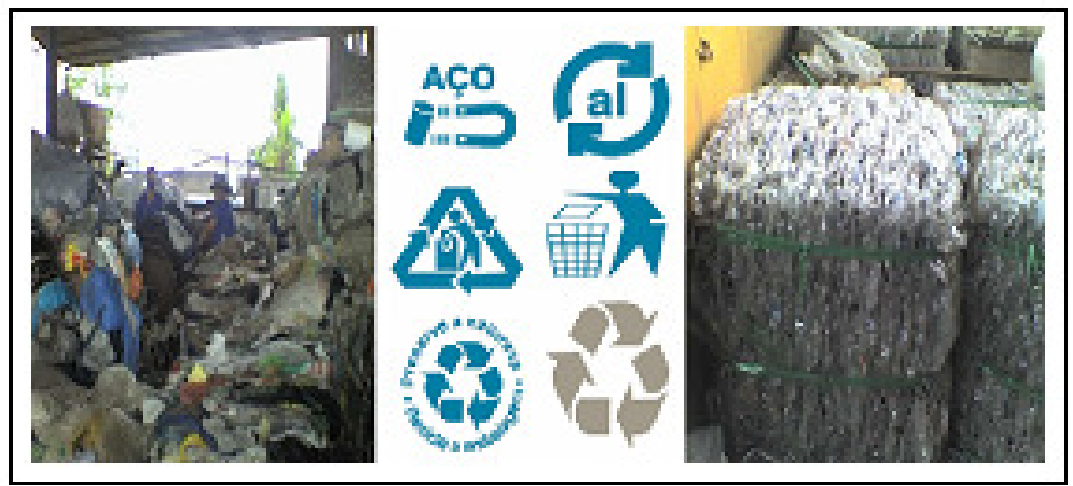

Figuras 02, 03 e 04 - Indicações de como a rotulagem ambiental pode auxiliar no processo de separação de materiais para a reciclagem. Fonte: Rosana R. Siqueira, 2010.

Embora seja percebido nas prateleiras dos supermercados o crescente número de rótulos e embalagens com apelos ambientais, algumas empresas do ramo de pesquisas com consumidores como a Market Analysis afirmam que no Brasil o número de produtos com apelo ecológico é bem menor que em países como os EUA. Neste sentido cabe salientar que esta empresa possui em sua carteira de clientes as mais caras e renomadas marcas de produtos e serviços do Brasil e do Mundo a exemplo da Coca-Cola, da Petrobras, instituições financeiras, ONGs entre outras.

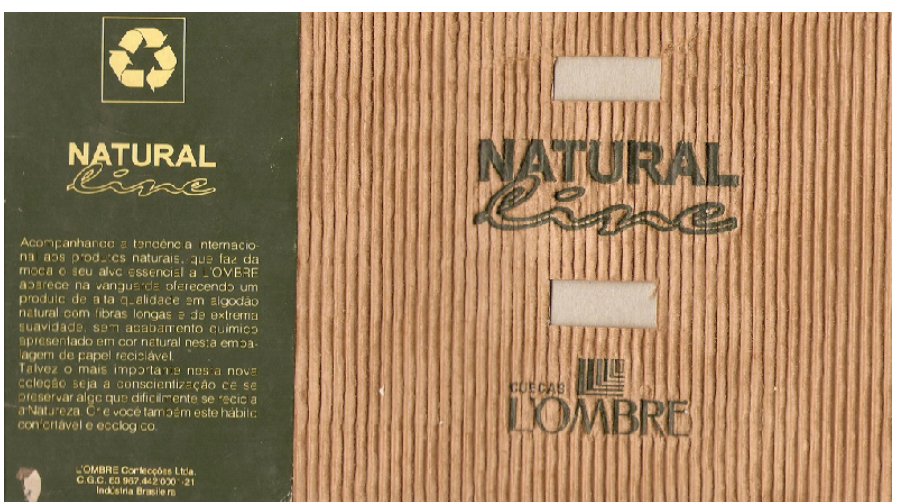

Figura 05 - O nome fantasia do produto pode confundir com informações consideradas ecológicas. Fonte: Embalagem de produto, arquivo pessoal.

A figura anterior (figura 05) é um exemplo de uma peça do vestuário íntimo que por ser feita de algodão é considerada um "produto natural", a embalagem feita em papel Kraft sugere um aspecto rústico acrescido do símbolo de reciclagem bem destacado, no qual o consumidor não consegue identificar se faz referência ao produto ou a embalagem. Os aspectos visuais da embalagem são reforçados pela mensagem: "Acompanhando a tendência internacional aos produtos naturais, que faz da moda seu alvo essencial [...].Nota-se o viés apelativo do produto embora 
não exista certificação que comprove as afirmações.

Neste contexto a Educação Ambiental (EA) pode ser uma aliada no processo de sensibilização do consumidor, devido a seu caráter interdisciplinar, a EA pode estar alinhada a estes propósitos uma vez que:

Art. $1^{\circ}$ Entende-se por educação ambiental os processos por meio dos quais o indivíduo e a coletividade constroem valores sociais, conhecimentos, habilidades, atitudes e competências voltadas para a conservação do meio ambiente, bem de uso comum do povo, essencial à saída qualidade de vida e sua sustentabilidade. (Dias, 2004, p. 202).

De acordo, o Programa Nacional de Rotulagem Ambiental em apoio a série de Normas de Certificação da série ISO 14.000 auxilia na padronização da linguagem e simbologia de forma a ser compreendida internacionalmente:

A série ISO/14000 é um grupo de normas que oferece subsídios para a fixação de padrões para SGA (sistema de gestão ambiental). Seu principal objetivo é harmonizar as normas nacionais e as regionais [...] transformando-as numa linguagem internacional. (BALLESTERO, 2001, p.269).

A rotulagem e declarações ambientais fornecem informações sobre um produto ou serviço em termos do seu caráter ambiental global, um aspecto ambiental específico ou qualquer um desses aspectos. Compradores e potenciais compradores podem usar essa informação na escolha de produtos ou serviços que desejem, baseados em considerações ambientais, assim como em outros. O fornecedor do produto ou serviço espera que o rótulo ou declaração ambiental seja efetivo para influenciar a decisão de compra em favor do seu produto ou serviço. Se o rótulo ou declaração ambiental tiver este efeito, a participação no mercado do produto ou serviço pode aumentar e outros fornecedores podem responder melhorando os aspectos ambientais dos seus produtos ou serviços para habilitá-los a usar os rótulos ambientais ou as declarações ambientais, resultando em redução dos efeitos ambientais negativos provocados por essa categoria de produtos ou serviços. (PROGRAMA NACIONAL DE ROTULAGEM AMBIENTAL, 2002).

Percebe-se então que o grande perigo encontra-se nas declarações voluntárias nas quais as empresas podem adicionar a embalagem do seu produto ou a propaganda se seu serviço, termos como "reciclável", "natural".

Alguns produtos a exemplo de: brinquedos, fósforos, capacetes, mamadeiras, chupetas, preservativos entre outros, trazem em suas embalagens rotulagens compulsórias 

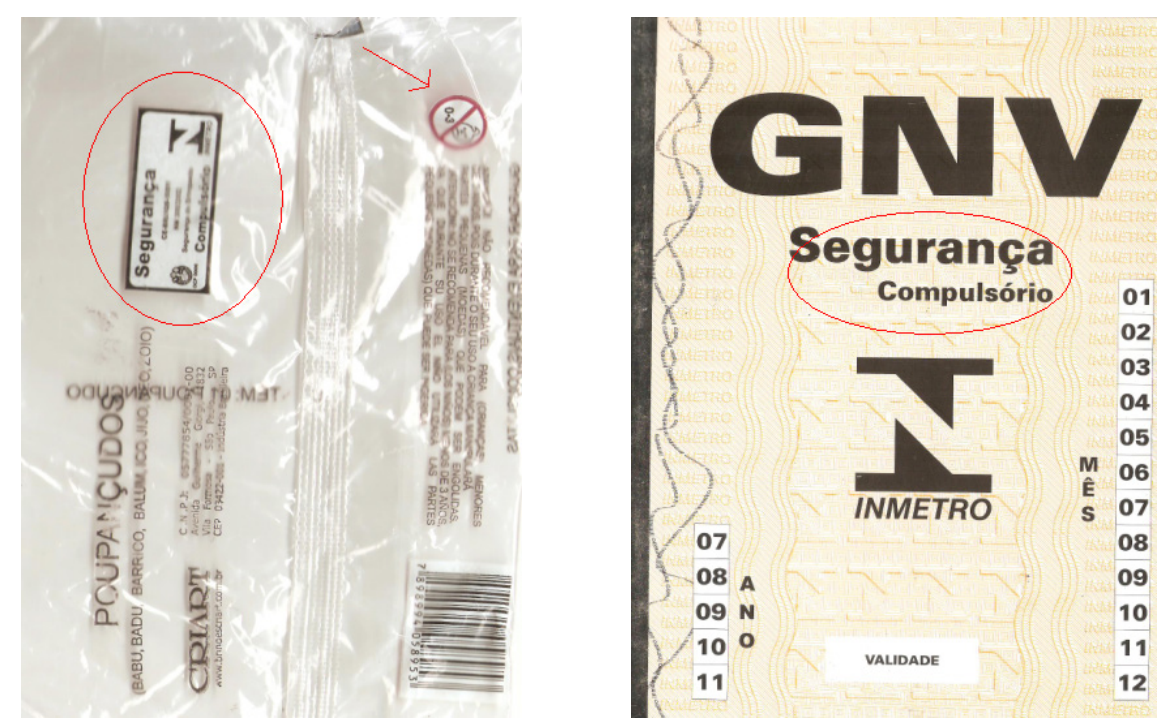

Figura 06 e 07 - indicação de Rotulagem compulsória de brinquedos e gás naturalveicular (GNV). Fonte: Embalagem de produto, arquivo pessoal.

\section{2 - Metodologia}

Realizou-se pesquisa bibliográfica exploratória em revistas, livros, e internet, além de visita a uma empresa de reciclagem localizada no Município de Estância Sergipe. A análise das embalagens apresentadas neste artigo partiu da observação dos aspectos que poderiam causar confusão ou dúvida na ocasião das compras do consumidor. Em estudos futuros cabe uma abordagem mais profunda sob a perspectiva da semiótica que poderá enumerar outros aspectos importantes a respeito da leitura e construção simbólica destas embalagens.

\section{3 - Abordagens negativas da publicidade "Verde"}

Dentre as abordagens mais graves relacionadas greenwashing destacam-se: a camuflagem dos impactos e custos ambientais do produtos apresentados como "verdes" ou "ecológicos" nos quais o processo de produção, a produção de gases de efeito estufa e a disposição irregular de resíduos não é levada em consideração. Assim embalagens que tragam o termo "100\% natural", "100\% ecológico" podem esconder processos produtivos altamente impactantes.

A falta de provas referentes aos benefícios prometidos nas embalagens, ou ainda informações vagas como "natural", ou que colocam em nome científico substâncias poluentes como amônia, mercúrio, chumbo, e alguns corantes cujo impacto ambiental não aparecem de forma compreensível na embalagem. Outro problema encontradoé a noção do "menos pior" na qual algumas ações de caráter pontual prometem reduzir impactos ambientais em grande escala, ou mesmo unem características ecológicas a produtos altamente poluidores como a produção de tabaco, combustíveis e minérios. 
O que seria um aliado ao consumo sustentável, constitui-se em um obstáculo no qual o consumidor não pode inferir com segurança se de fato realiza uma escolha positiva ou negativa para o meio ambiente. Neste sentido o Programa de Rotulagem Ambiental da ABNT colabora com a criação de normas que possam divulgar informações sobre o ciclo de vida dos produtos.

O programa de Rotulagem Ambiental da ABNT, de caráter voluntário, visa a demonstrar a conformidade de produtos ou serviços a critérios estabelecidos pelo Grupo de Rotulagem Ambiental - GRA, considerando aspectos relacionados ao ciclo de vida destes produtos ou serviços. (Procedimento Geral da Marca ABNT- Qualidade Ambiental, 2009, p.02)

Neste sentido ao atribuir benefícios a produtos e serviços a empresa deve ter respaldo técnico e certificação dos processos mencionados na publicidade, de acordo o consultor Luiz Carlos Porto acrescenta:

Qualquer profissional da área ambiental percebe claramente que trata-se de um comercial criado por profissionais de propaganda, sem qualquer respaldo técnico. Assumir que um produto é mais "ecológico" que o outro, ou até que seja "100\% ecológico" como a propaganda afirma, é uma simplificação inadmissível [...] não cita nenhum estudo técnico ou certificação de instituição independente que justifique os atributos ambientais alegados. Além do mais, essa forma de autodeclaração ambiental vai contra as recentes Normas Técnicas da Série ISO 14000.

Um famoso exemplo de greenwashing amplamente divulgado refere-se à produção de determinada marca de tradicionais esponjas de aço. Logo a seguir pode-se observar o exemplo da polêmica embalagem que não está conforme com as instruções normativas sobre utilização de termos ligados a sustentabilidade.
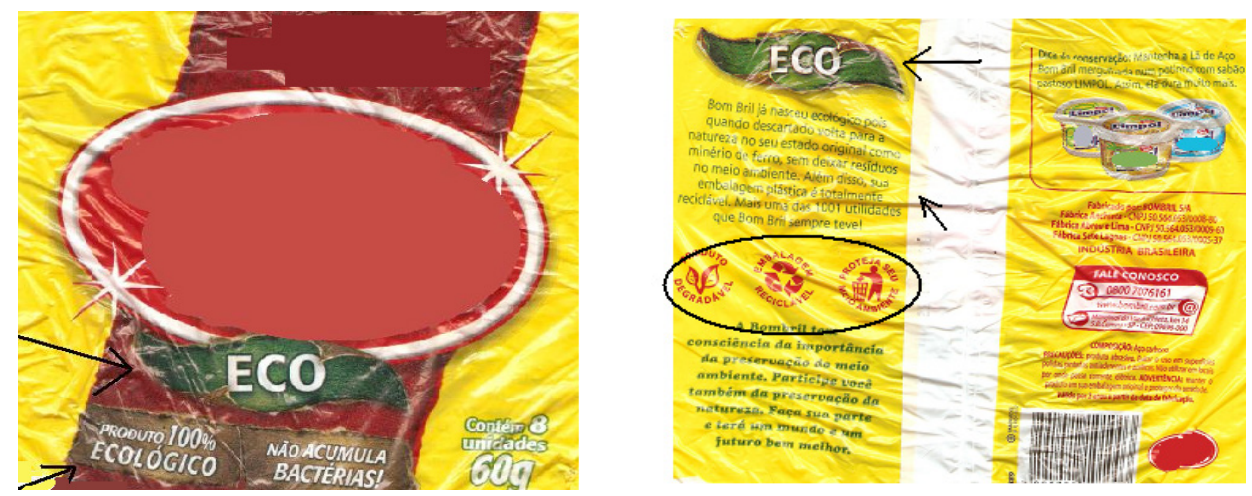

Figuras 08 e 09- Embalagens que misturam símbolos de rotulagem ambiental com publicidade podem confundir o consumidor ao afirmar que são " $100 \%$ ecológicos".

Fonte: Embalagem de produto, arquivo pessoal. 
A abordagem da publicidade anterior trazia termos mas condizentes com o produto uma vez que este de fato não é "100\% ecológico" , mas sim "biodegradável” . No entanto a abordagem atual traz no verso a mensagem é enfática:

[...] já nasceu ecológico, pois quando descartado volta para a natureza em seu estado original, como minério de ferro, sem deixar resíduos no meio ambiente. Além disto, sua embalagem plástica é totalmente reciclável [...]. (EMBALAGEM DE PRODUTO, 2010).

Observa-se assim que abordagem publicitária não considera os resíduos do processo produtivo, bem como os impactos da extração do minério de ferro. Uma vez descartado seria impossível o produto voltar à natureza "[...] em seu estado original" como prometido. Assim a utilização dos termos eco, natural, natura, verde, Green, bem como nomes de instituições beneficentes tem sido amplamente divulgado em embalagens com vistas a apresentar benefícios a produtos e serviços. Torna-se inclusive difícil para o consumidor observar o que faz parte das informações relativas à rotulagem e aquelas relativas à publicidade. $\mathrm{O}$ exemplo da embalagem a seguir deixa evidente a confusão de terminologias.

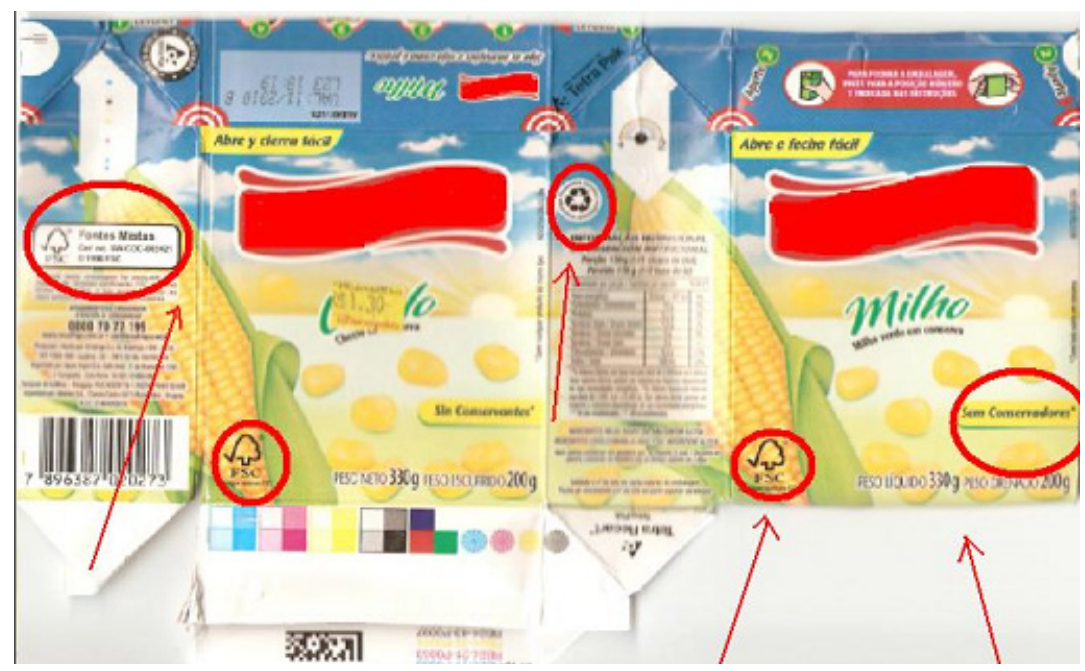

Figura 10- Embalagem de produto com excesso de terminologias

Fonte: Embalagem de produto, arquivo pessoal. 
A seguir pode-se observar a inclusão de termos ligados a projetos sócio-ambientais.

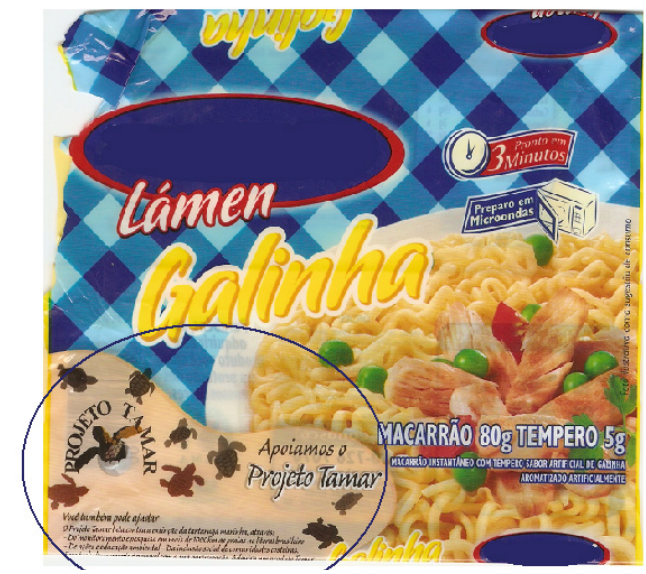

Figura 11- Exemplo de produto que agrega apoio a projetos ambientais.

Fonte: Embalagem de Produto, arquivo pessoal.

\section{1- Código Nacional de Autoregulamentação Publicitária- CONAR}

Desta forma, diante das mudanças rumo a sustentabilidade, o Conselho de Ética da Associação (CONAR) observou a necessidade de reavaliar o Artigo 36, que atualmente traz normas mais rígidas para coibir publicidade abusiva ou enganosa que utilize termos ligados a sustentabilidade e a entidades sociais.

O CONAR é uma associação fundada em 1980 em São Paulo a partir da necessidade de liberdade de expressão e combate à censura na criação publicitária. Sendo o Código Nacional de Autoregulamentação Publicitária aprovado em ano de 1978, atribuindo a entidade as seguintes processos:

O CONAR atende a denúncias de consumidores, autoridades, dos seus associados ou ainda formulados pela própria diretoria. Feita a denúncia, o Conselho de Ética do CONAR - órgão soberano na fiscalização, julgamento e deliberação no que se relaciona à obediência e cumprimento do disposto no Código - se reúne e julga, garantindo amplo direito de defesa ao acusado. Se a denúncia tiver pertinência, o CONAR recomenda aos veículos de comunicação a suspensão da exibição da peça ou sugere correções à propaganda. Pode ainda advertir anunciante e agência. (<www.ideiasustentavel.com.br/educacao $>$. Acesso: 07 de jun. de 2011).

As normas relativas ao combate ao greenwashing integram o Artigo 36 do Código, entrando em vigor a partir de $1^{\circ}$ de Agosto de 2011, considerando-se que:

A publicidade deverá refletir as preocupações de toda a humanidade com os problemas relacionados com 
assim, serão vigorosamente combatidos os anúncios que, direta ou indiretamente, estimulem: a poluição do ar, das águas, das matas e dos demais recursos naturais; a poluição do meio ambiente urbano; a depredação da fauna, da flora e dos demais recursos naturais; a poluição visual dos campos e das cidades; a poluição sonora; o desperdício de recursos naturais. (<www.conar.org.br>. Acesso 26 de agos. 2011).

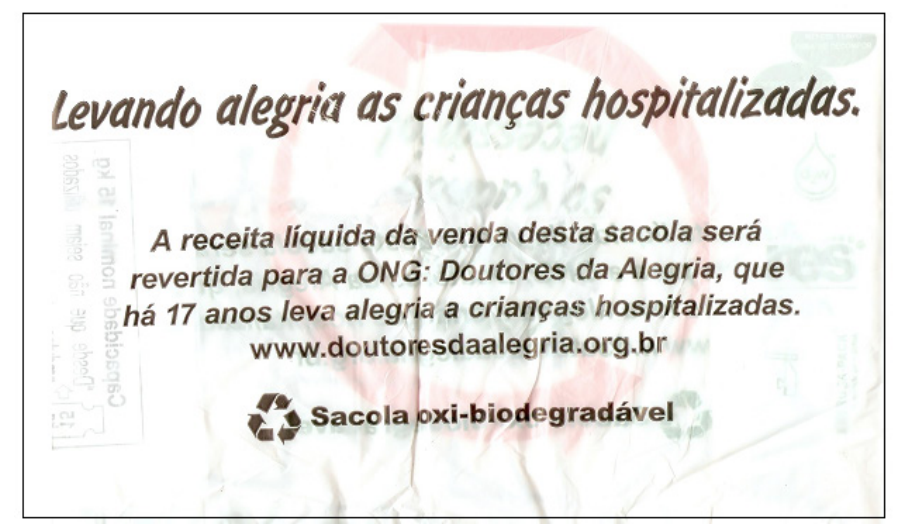

Figura 12 - Exemplo de produto que agrega apoio a projetos sociais. Fonte: Embalagem de Produto, arquivo pessoal.

Quanto às abordagens de marketing relacionadas às causas e instituições sócio- ambientais, só poderão ser relacionadas a produtos e serviços com autorização expressa das instituições, devendo respeitar também as normativas constantes no Código do CONAR. A figura 10 é um exemplo de ação socioambiental na qual a venda de sacolas oxi-degradáveis (cujo plástico deteriora-se com facilidade) reverte valores ao referido projeto social.

Desta forma as abordagens publicitárias devem respeitar os seguintes princípios: 


\begin{tabular}{|c|c|}
\hline Veracidade & $\begin{array}{l}\text { As informações e alegações veiculadas deverão } \\
\text { ser verdadeiras, passíveis de verificação e de } \\
\text { comprovação, estimulando-se a disponibiliza- } \\
\text { ção de informações mais detalhadas sobre as } \\
\text { práticas apregoadas por meio de outras fontes } \\
\text { e materiais, tais como web sites, SACs (Serviços } \\
\text { de Atendimento ao Consumidor), entre outros. }\end{array}$ \\
\hline Exatidão & $\begin{array}{l}\text { Asinformaçõesambientaisdevem serexatasepre- } \\
\text { cisas, não cabendo informações genéricas e vagas; }\end{array}$ \\
\hline Pertinência & $\begin{array}{l}\text { As informações ambientais veiculadas devem ter } \\
\text { relação com os processos de produção e comer- } \\
\text { cialização dos produtos e serviços anunciados; }\end{array}$ \\
\hline Relevância & $\begin{array}{l}\text { O benefício ambiental salientado deve- } \\
\text { rá ser significativo em termos do impac- } \\
\text { to total do produto e do serviço sobre o } \\
\text { meio ambiente, em todo seu ciclo de vida, } \\
\text { ou seja, na sua produção, uso e descarte }\end{array}$ \\
\hline Concretude & $\begin{array}{l}\text { O benefício ambiental salientado deve- } \\
\text { rá ser significativo em termos do impac- } \\
\text { to total do produto e do serviço sobre o } \\
\text { meio ambiente, em todo seu ciclo de vida, } \\
\text { ou seja, na sua produção, uso e descarte }\end{array}$ \\
\hline Pertinência & $\begin{array}{l}\text { É aconselhável que as informações socioam- } \\
\text { bientais tenham relação lógica com a área de } \\
\text { atuação das empresas, e/ou com suas mar- } \\
\text { cas, produtos e serviços, em seu setor de ne- } \\
\text { gócios e mercado. Não serão considerados } \\
\text { pertinentes apelos que divulguem como be- } \\
\text { nefício socioambiental o mero cumprimen- } \\
\text { to de disposições legais e regulamentares } \\
\text { a que o anunciante se encontra obrigado. }\end{array}$ \\
\hline Relevância & $\begin{array}{l}\text { Os benefícios socioambientais comunicados de- } \\
\text { verão ser significativos em termos do impacto } \\
\text { global que as empresas, suas marcas, produtos } \\
\text { e serviços exercem sobre a sociedade e o meio } \\
\text { ambiente - em todo seu processo e ciclo, desde a } \\
\text { produção e comercialização, até o uso e descarte. }\end{array}$ \\
\hline Absoluto & $\begin{array}{l}\text { Tendo em vista que não existem compen- } \\
\text { sações plenas, que anulem os impactos so- } \\
\text { cioambientais produzidos pelas empresas, a } \\
\text { publicidade não comunicará promessas ou } \\
\text { vantagens absolutas ou de superioridade im- } \\
\text { batível. As ações de responsabilidade socio- } \\
\text { ambiental não serão comunicadas como evi- } \\
\text { dência suficiente da sustentabilidade geral da } \\
\text { empresa, suas marcas, produtos e serviços. }\end{array}$ \\
\hline
\end{tabular}

Quadro 01 - Princípios criados pelo CONAR no combate ao greenwashing. Fonte: Baseado em http://www.ideiasustentavel.com.br/2011/06/conar-crianormas-eticas-para-apelos-de-sustentabilidade-na-publicidade/ Acesso: 


\section{4 - Conseiderações Finais}

Desta forma é previsto no Programa Nacional de Educação Ambiental no âmbito das linhas de ação e estratégias (ProNEA, 2005, p. 46) o estímulo a educação voltada para "Concessão às empresas ambientalmente corretas, de certificação ambiental análoga a ISO, como incentivo à manutenção de seu compromisso socioambiental”.

Neste sentido ações de EA podem intervir de forma positiva na sensibilização de consumidores e empresários.

Quanto às empresas e agências de marketing faz-se necessário a busca constante de informações e o respaldo técnico e acadêmico das informações propagadas como benefícios de produtos e serviços, além de atentar para impactos socioambientais "camuflados" nos processos de produção e descarte. Assim percebe-se que não basta apenas incrementar um mix de marketing (preço, praça, produto e promoção), é preciso considerar o "perigo" de ostentar vantagens inexistentes.

NOTA:

A sigla ProNEA (Programa Nacional de Educação Ambiental) refere-se ao programa instituído em 1999 e não ao programa de 1994 (PRONEA).

\section{5 - Referências}

BRASIL. Ministério do Meio Ambiente. Rotulagem Ambiental: documento base para o programa brasileiro de rotulagem ambiental. Brasília: MMA/SPDS, 2002.209p.

BRASIL. ProNEA. Ministério do Meio Ambiente. 3.ed. Brasília: Ministério do Meio Ambiente, 2005. 102 p.

BRASIL. Procedimento Geral da Marca ABNT- Qualidade Ambiental, 2009, p.02. BALleSTERO, Maria Esmeralda. Administração da Qualidade e da Produtividade: abordagens do processo administrativo. São Paulo: Atlas, 2001. 357 p.

CONAR. Conselho Nacional de Autoregulamentação Publicitária. Disponível em: < www.conar.org.br>. Acesso em: 26 de agos. 2011.

DIAS, Genebaldo Freire. Educação Ambiental: princípios e práticas. 9. Ed. São Paulo: Gaia, 2004, p. 202. <www.ideiasustentavel.com.br/educacao $>$. Acesso em: 07 de jun. 2011 $<$ www.ideiasustentavel.com.br/2011/06/conar-cria-normas-eticas-para-apelos-de-sustentabilidade-na-publicidade/>. Acesso em: 03 de jul. 2011.

<http://wp.clicrbs.com.br/blogarpuro/2010/07/18/marketing-ambiental-o-exemplo-valioso-da-bombril/ >. Acesso em: 26 de agos. 2011. 